\title{
Forest Stand Growth Models: What For?
}

\author{
by
}

\author{
Stephen J. Titus and Robert T. Morton ${ }^{1}$
}

\begin{abstract}
Until very recently foresters have relied on infrequent inventories to provide static descriptions of large forest areas for management planning. With the quantum increases in computing power, the massing of forestry data, and the increasing pressure for effective management planning, it is becoming necessary to view the forest as dynamic, and subject to manipulation for management purposes. Prediction of changes to forest structure and yield must be made to update old data and project stands into the future. This paper reviews the current sources of literature on growth and yield, discusses basic types and components of growth models, and gives some examples of important uses for growth and yield models. The future will see increased use of computers for analysis of forestry data including even more sophisticated growth and yield models linked to both inventory and decision making processes.
\end{abstract}

\section{Résume}

Jusqu'à tout récemment, les forestiers se fiaient à des inventaires parsemés pour obtenir une description statique des grandes étendues forestières pour planifier leurs aménagements. Avec l'augmentation de la puissance de l'informatique, la quantité importante des données forestieres et la pression accrue pour une planification efficace des aménagements forestiers, il est devenu nécessaire de voir la forêt de façon dynamique et sujet à des manipulations pour fins d'aménagement. Prévoir des modifications dans la structure et le rendement des forêts est devenu nécessaire afin de mettre à jour les données anciennes et de projeter dans le future les peuplements. Cet article revoie les sources courantes qui existent dans la litterature sur la croissance et les rendements, discute des types de base et des composantes des modèles de croissance et de rendement et donne quelques exemples d'utilisations importantes de modèles de croissance et de rendement. Le future amenera une augmentation importante de l'utilisation de l'informatique pour l'analyse des données forestiéres incluant des modèles encore plus sophistiqués de croissance et de rendement qui seront associés aux inveritaires et aux processus de prises de décision.

\section{Introduction}

Until very recently foresters have relied on infrequent inventories to provide static descriptions of large forest areas for management planning. Inventories usually started with new vegetation type maps and data and ignored results of previous inventory projects. Today, with the incredible computational power of computers, data are being maintained and augmented rather than discarded prior to each new inventory. The retention of detailed records makes more complex analyses and summaries possible. Management planning is also becoming more complex, with additional data requirements and the need to predict changes in forest structure and yield.

This paper reviews the current sources of literature on growth and yield, discusses basic types and components of growth models, and presents some examples of important uses for growth and yield models.

Stephen J. Titus is Associate Professor, Department of Forest Science, University of Alberta. Robert T. Morton is a principal with Silvacom Ltd., Edmonton, Alberta. This manuscript was prepared while the junior author was a Research Associate with the Department of Forest Science. University of Alberta.

\section{Growth and Yield Literature}

For the practicing Canadian forester the sources of literature on growth and yield are somewhat limited. In the last 10 years there have been about half-a-dozen papers in the Forestry Chronicle dealing with growth and yield, and perhaps another six dealing with other measurement topics. Considering that this is the journal that is most accessible to the average Canadian forester, this could easily be termed "poorly stocked". The Canadian Journal of Forest Research and publications of the Canadian Forestry Service provide much more literature on growth and yield research, but these are not as readily available to many foresters. The remaining readily available references are texts used by the forestry schools, most commonly Husch, Miller and Beers (1982) and Avery and Burkhart (1983). These are both recently updated, have good bibliographies, and are the only commonly available references that treat the growth and yield topic in a comprehensive way. A recent workshop at Lakehead University (Brown and Clarke 1980) summarized current research in growth and yield.

Some additional literature is available in the form of user's 
manuals for the various growth models developed by other researchers. Since many of these models continue to be modified and improved, the unfortunate result is that documentation is often incomplete or obsolete by the time it is available.

\section{Components of a Growth Model}

Growth is defined as the change in size, i.e. periodic increment of a tree in response to life processes. These processes are controlled both by the inherent potential of the tree and the physical ecosystem in which the tree exists. This ecosystem is an example of systems generally; they consist of a collection of interacting components within defined boundaries, governed by set rules of operation. A model is a (usually) quantitative description of this physical system, consisting of one or more mathematical relationships. Individual model components are mathematical equations describing specific components of growth, such as diameter and height increment. The whole model represents a compromise between accuracy and simplicity. It allows testing management alternatives under simulated time to determine the system response. Tree, stand and forest level models represent different levels of resolution. They are commonly presented as computer programs that facilitate manipulation of inouts and outputs, rapid solution and the ability to summarize conditions of the system at various points in simulated time.

Models can be classed as either simulation or optimization. Simulation models require that the user specify treatment types and levels; no optimal solution is given. The user must. through trial and error, run the model under various options and iteratively search for an optimal solution. An optimization model attempts to maximize an objective function through an optimal combination of competing activities and activity levels.

All forest growth models depict the development of stands over time. To do this the basic components of tree establish- ment, growth, and mortality must be included in some form. In addition, specifications are usually required for the initial site conditions, a management plan, and provisions for reporting stand summary statistics at the appropriate times in the simulated development of the stand. Depending on the complexity of the model, these components may be implicity or explicity included.

A normal yield table is a familiar example of a growth model. Basically, it is simply a statement of the relation:

Volume $=f($ Age, Site, Species $)$

Establishment of the stand is implicitly included in this model by assuming natural regeneration appropriate to the species. Net change, not survivor growth, is obtained as the difference in volume at two points in time, and this also includes the impact of volume lost due to trees dying (mortality). Site index is the measure of site conditions, and usually stands are assumed to be natural and unmanaged. The estimates themselves are usually simple tables of volume at different ages. Some yield tables also summarize number of trees, average diameter, height or other stand characteristics.

Yield tables are just one of a number of different types of models of varying complexity. The more complex models deal with these same components but in more depth. Table 1 illustrates the four primary model types and their components. The individual components may take linear or nonlinear forms. Discussion of the theoretical basis and the application of these functions may be found in Smith and Kozak (1984), Clutter et al. (1983), Payandeh (1983), Yang et al. (1978), Hunt (1982). Nokoe (1978). Grosenbaugh (1965) and Cooper (1961)

\section{Types of Growth Models}

The most commonly used classification for growth models was first presented by Munro (1974). Two primary types of models are recognized: single-tree and whole-stand. In a

\section{Table 1. Inputs, outputs and components of various model types}

\begin{tabular}{lr}
\hline Model Type & Inputs \\
\hline 1. Whole stand & $\begin{array}{r}\text { site } \\
\text { age } \\
\text { density } \\
\text { 2. Whole stand, with diameter distribution }\end{array}$ \\
& $\begin{array}{r}\text { site } \\
\text { density }\end{array}$ \\
3. Individual tree, & Tree OBH list by species \\
distance independent & with perhaps HT, CR
\end{tabular}

4. Individual tree, distance dependent

Where:

$\mathrm{OBH}$ is diameter at breast height

$\mathrm{HT}$ is total tree height

MORT is tree mortality

VOL is total or merchantable tree volume

CR is crown ratio (or other crown attribute)

"i" is the tree subscript
As in 3 with addition of coordinate locations for each tree
Components/Functions

Outputs

$\mathrm{VOL}=f($ age, site, density $)$

VOL $=f($ age, site, density $)$ pdf assumed with

Coefficients $=f($ age, site, density $)$

Stand Table $=\uparrow($ pdi, density $)$

$V O L=\Sigma V O L(i)$

VOL $(i)=f(D B H, H T, S P P)$

$\mathrm{DBH}(i)=\sum$ Increments

$H T(i)=$ zincrements or $H T(i)=f(D B H(i))$

Increment $\{i\}=$ fidensity age , site, $\mathrm{CR}, \mathrm{DBH}, \mathrm{HT})$

MORT $(i)=f($ Increment,DBH .

Stand Attributes)

As in 3 with

Increment $(i)=f($ Location, density, age,site, CR,DBH,HT)
Average Volume, Basal Area

Diameter. Height

As in 1 with addition of Stand Tables

As in 2

As in 2 with ability to map stands and/or present in 3 dimensions 
whole-stand model projections are made using stand characteristics such as age, site, and density. This contrasts with a single-tree model which makes projections for individual trees and then aggregates as necessary for stand summaries. Growth models have been developed for both even-and uneven-aged forest stands although the uneven-aged stand is the more difficult to model (Curtis 1981).

The typical whole-stand model predicts stand volume or biomass as a function of age, site index, and density. Common examples are the traditional normal or empirical yield tables (Johnstone 1977, Kabzems 1971, MacLeod and Blyth 1955. Plonski 1956). To increase the utility of yield tables, extensions have been proposed that provide estimates of the average diameter, and its distribution (Burkhart 1977). Typically this is presented as a stand table. Average diameter must be predicted first since yield predictions are not based on individual tree characteristics. The diameter distribution may be based on an assumed distribution, or a general distribution function, such as the Weibull probability density function ( $p d f)^{2}$, may be used with the parameters of the model estimated as functions of stand characteristics. These models are referred to as either whole-stand/diameter-free or whole-stand/diameterdistribution models (Hann 1978).

Individual tree models may be either distance-dependent or distance-independent depending on whether individual tree locations are known. The use of tree location, in relation to other competing trees, to evaluate establishment, growth, and mortality is more difficult but should be theoretically sound since competition for growing space should affect these components.

Early work by Newnham and Smith (1964). Bella (1970) and Hegyi (1974) resulted in distance-dependent models for Douglas-fir, aspen and jack pine. More recently, Mitchell (1975) developed a more detailed distance-dependent model for Douglas-fir which includes the crown development as well. Distance-independent models have been constructed for aspen (Grabowski 1981) but none of these models has been fully utilized by managers.

Avery and Burkhart (1983) use the terminology "direct" and "indirect" when referring to methods for predicting growth and yield. Direct methods are those based on growth measurements for the stand being projected. Stand table projection is the most common direct growth projection method. Indirect methods base growth projections on relationships derived from the study of many stands. This category includes most yield tables and individual tree models. A combination of direct and indirect methods is also possible if measurement data is used to calibrate the growth model. Stage's prognosis mode! (Wykoff ef al. 1982) and Krumland's (1982) redwood model both use this approach.

\section{Uses of Growth Models}

Models are abstractions of a real system. They allow us to summarize what we know about the dynamics of stand development. Depending on how much we know, they may be complex or simple. They also allow us to make predictions about stand development, and this is the main reason for the continuing interest in their development. These predictions can be used in a variety of applications including 1 ) inventory update, 2) yield table construction, 3) development of silvicultural prescriptions, and 4) management planning. Without growth models of some sort, and yield tables are the most

The Weibuli pofis one of a number of mathematical functions used to describe diameter distributions fe frequencies by diameter class. It has a single peak. and is very flexible in the shape that the curve can assume. The three parameters of this function describe the location. scale (spread) and shape of the diameter distribution. These parameters themselves can be functions of stand characteristics such as age, density or average stand height. common example, we would be hard pressed to make intelligent management decisions.

Since many inventories are conducted over several years, there are changes in the sampled stands due to ingrowth, increment, and mortality. Cyclic and older inventories also provide data about forest areas that can be updated using an appropriate growth model. Individual-tree models can be used to update inventory plot records whereas whole-stand models can only update average stand values. The quality of updated inventory records depends on quality of the model and the length of growth projection.

Yield tables provide predictions of natural unmanaged stand volume at different ages, for different categories of species, site quality, and sometimes density. Growth models can be the basis for making predictions of yield under managed conditions where density and other treatments are controlled. Both single-tree and whole-stand models can be the basis for constructing yield tables.

Virtually unlimited opportunities for studying the dynamics of stand development are possible by evaluating predictions made by the model. Silvicultural manipulations may be simulated and the response observed quickly and easily. However, manipulations must always be made with caution since the behavior of the model, especially when extrapolated, may or may not mimic the behavior of real forest stands. If predictions are inconsistent with known or expected behavior of real stands, then we must determine why the difference is occurring. The model may need modification, or we may need to conduct a field experiment to test the conclusions of the model against real stands. Rather than invalidating the model this gives us the chance to improve it and strengthen our understanding of the way forest stands grow and develop.

Management planners can effectively use growth models by projecting the stand under planned management practices to evaluate their impact before implementation. Many different kinds of "what if" questions can be addressed easily and cheaply. More commonly, however, harvest scheduling models such as Timber RAM (Navon 1971) are used with yield tables produced for natural and second growth stands using an appropriate growth model. This use of growth models is usually more restricted since only a limited number of yield tables are allowed and these are usually allocated on the basis of vegetation classes related to species and site categories

From a more general viewpoint, models provide a framework for developing and testing theory. They enable us to identify strengths and weakness in our current knowledge. Research efforts can be guided into directions needed to improve the model, and in some cases experiments can be performed on the model more easily than on the real system. It can assist in education and training by showing how the model components work and interrelate with each other. In general, models aid in consolidating and organizing our knowledge about complex systems. For management, models are useful in a variety of ways including simulation, prediction, optimization, and control.

\section{Sources of Growth Models}

In spite of the number of growth models that have been developed in recent years, the typical user in Canada would be lucky to find one or two models that might be similar to the region and sites of interest. The desired uses of the model are likely to limit the selection further and may leave no models that are appropriate. In this case only two possibilities remain after identifying the type of model most appropriate for desired uses: 1) build your own model or 2) modify a model from some other region. This is a difficult choice because either alternative requires a lot of effort. Both require development of 
necessary relationships followed by either building the input and output structure or disassembling and modifying the structure developed by someone else. The only way to know exactly how a model works is to understand the computer code and especially the relationships on which it is based. The biological relevance and logic of the growth functions are of prime importance (Hunt 1982, Landsberg 1981). In addition, Burkhart (1981) and Clutter (1980) stress the utilitarian approach to selecting models based on efficiency, flexibility and the amount and type of summary detail provided. Recent articles by Brand and Holdaway (1983) and Buchman and Shifley (1983) provide benchmarks for the evaluation and selection of various model types.

\section{Conclusions}

Growth models may be nothing more than the familiar yield tables most foresters have used on-the-job. Increasingly, however, they are becoming more elaborate and require a computer to make projections. This needn't be more complex than the old yield tables, at least not from the standpoint of use. The models themselves are more complex but most managers only care about the quality of the predictions. The main point is that we need good information to make sound management decisions, and growth models are a primary tool for us to use.

\section{References}

Avery, T.E. and H.E. Burkhart. 1983. Forest Measurements. Third ed. McGraw-Hill. New York.

Bella, I.E. 1970. Simulation of growth, yield and management of aspen. Ph.D. thesis, Univ. British Columbia.

Brand, G.J. and M.R. Holdaway. 1983. Users need performance intormation to evaluate models. J. For. 81: 235-237, 254

Brown, K.M. and F.R. Clarke (editors). 1980. Forecasting torest stand dynamics. Proc. Workshop held at the School of For.. Lakehead University, Thunder Bay, Ontario.

Buchman, R.G. and S.R. Shifley. 1983. Guide to evaluating fores: growth projection systems. J. For. 81:232-234.

Burkhart, H.E. 1977. Stand modclling for radiata pine in New Zealand N.Z. J. For 22: 297-307

Burkhart, H.E. 1981. Comparison of growth and yield prediction models for loblolly pine. School For. and Wildt. Res., Va. Polytech. Inst. and State Univ., FWS-2-81.

Burkhart, H.E., Q.V. Cao, and R.C. Lemin. 1982. Diameter distributions and yields of thinned loblolly pine plantations. School For. and Wildl. Res. Va. Polytech. Inst. and State Univ.. FWS-1 -82.

Clutter, J.L. 1980. Forest management opportunities for the future. In: Forecasting Forest Stand Dynamics (Ed. Brown, K.M. and F.R Clarke), Lakehead University. Thunder Bay.

Clutter, J.L., Fortson, J.C., Pienaar, L.V., Brister, G.H. and R.L. Bailey. 1983. Timber Management: a Quantitative Approach. J. Wiley and Sons, New York.

Cooper, C.F. 1961. Equations for the description of past growth in even-aged stands of Ponderosa pine. Forest Sci. 7: 72-79.

Curtis, R.O. 1981. Yield tables past and present. J. For. 70: 28-32.

Grabowski, T.I. 1981. A stand growth model for trembling aspen in the Prairie Provinces of Canada. M.Sc thesis, Univ Alberta.

Grosenbaugh, L,R. 1965. Generalization and reparameterization of some sigmoid and other nonlinear functions, Biometrics 21 : $708-714$.

Hann, D.W. 1978. The development and evaluation of an even and uneven aged ponderosa pine, Arizona fescue stand simulator with managerial decision making. Ph.D. thesis, Univ. Wash, Seattle.

Hegyi, F. 1974. A simulation model for managing jack pine. In: Growth Models for Tree and Stand Simulation (Ed. J. Fries) Royal College of Forestry, Stockholm

Hunt, R. 1982. Plant Growth Curves: The Functional Approach to Plant Growth Arialysis. Edward Arnold, London.

Husch, B., C.I. Miller and T.W. Beers. 1982. Forest Mensuration. Wiley \& Sons, New York.
Johnstone, W.D. 1977. Interim equations and tables for the yield of fully stockes spruce-poplar stands in the mixed wood forest section of Alberta. Can. For. Serv. Inf. Rep. NOR-X-175

Kabzems, A, 1971. The growth and yield of well-stocked white spruce in the mixedwood section of Saskatchewan. Sask. Dep. Nat. Res., Tech. Bull. No. 5.

Krumland, B.E. 1982. A tree-based forest yield projection system for the North Coast Region of California. Ph.D. thesis, Univ. California. Berkeley.

Landsberg, J.J. 1981. The number and quality of the driving variables needed to model tree growth. Studia Forestalia Suecia 160: 43-50.

MacLeod, W.K. and A.W. Blyth. 1955. Yield of even-aged fully stocked spruce-poplar stands in northern Alberta. Can. Dep. For., For. Res. Br. Tech. Note No. 18.

Mitchell, K.J. 1975. Dynamics and simulated yield of Douglas-fir. Forest Sci. Monog. No. 17.

Munro, D. 1974. Forest growth models - A prognosis. In: Growth Models for Tree and Stand Simulation (Ed. J. Fries) Royal College of Forestry, Stockholm.

Navon, D.I. 1971. Timber RAM- and long-range planning method for commercial timber lands under multiple-use management. USDA For. Serv. Res. Pap. PSW-70.

Newnham, R.M. and J.H.G. Smith. 1964. Development and testing of stand models for Douglas-fir and lodgepole pine. For. Chron. 40: 494-502.

Nokoe, S. 1978. Demonstrating the flexibility of the Gompertz function as a yield model using mature species data. Commonw. For. Rev. 57: 35-42

Payandeh, B. 1983. Some applications of nonlinear regression models in forestry research. For. Chron. 59: 244-248.

Plonski, W.L. 1956. Normal yield tables. Ontario Dep. Lands and Forests Rep. No. 24.

Smith, J.H.G. and A. Kozak. 1984. New non-linear models can improve estimates of growth and yield. Commonw. For. Rev. 63: $41-45$.

Wykoff, W.R., Crookston, N.L. and A.R. Stage. 1982. User's guide to the Stand Prognosis Model. USDA For. Serv. Gen. Tech. Rep. INT-133.

Yang, R.C., Kozak, A. and J.H.G. Smith. 1978. The potential for the Weibull type functions as flexible growth curves. Can. J. For. Res. 8: 424-431

\section{Woodlot Service (1978) Ltd.}

"All Matters Pertalning to Forestry"

\author{
GORDON B. YOUNG, B.SC.F., M.F. \\ Registered Professional Forester
}

320 Maple Street

Bus.: $506-472-3396$

Fredericton, N.B. 